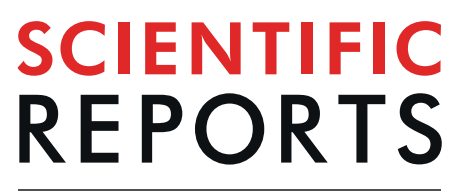

\title{
Incidence of diabetes mellitus in Spain as results of the nation-wide cohort di@bet.es study
}

\author{
G. Rojo-Martínez $\left(\mathbb{D}^{1,2^{*}}, \mathrm{~S}\right.$. Valdés $\mathbb{D}^{1,2}$, F. Soriguer $\mathbb{D}^{1,2}$, J. Vendrell $\mathbb{D}^{1,3}$, I. Urrutia $(\mathbb{D})^{1,4,5}$, \\ V. Pérez ${ }^{6}$, E. Ortega $\mathbb{1}^{7,8}$, P. Ocón $\mathbb{1}^{6}$, E. Montanya $\mathbb{1}^{1,9}$, E. Menéndez $\mathbb{1}^{5,10}$, \\ A. Lago-Sampedro $\mathbb{1}^{1,2}$, T. González-Frutos $\mathbb{D}^{4}$, R. Gomis $\mathbb{1}^{1,7}$, A. Goday $\mathbb{D}^{8,11}$ \\ S. García-Serrano $\mathbb{D}^{1,2}$, E. García-Escobar $\mathbb{D}^{1,2}$, J. L. Galán-García $\mathbb{1}^{12}$, C. Castell $\mathbb{1}^{13}$, \\ R. Badía-Guillén ${ }^{2}$, G. Aguilera-Venegas ${ }^{10}{ }^{12}$, J. Girbés ${ }^{14,19}$, S. Gaztambide $\mathbb{1}^{1,5,15}$, \\ J. Franch-Nadal $\mathbb{1}^{1,16,19}$, E. Delgado $\mathbb{C}^{5,10,19}$, F. J. Chaves $\mathbb{B}^{1,17,19}$, L. Castaño $\mathbb{D}^{1,4,5,19}$ \& \\ A. Calle-Pascual $\mathbb{1}^{1,18,19}$
}

Our aim was to determine the incidence of type 2 diabetes mellitus in a nation-wide population based cohort from Spain (di@bet.es study). The target was the Spanish population. In total 5072 people older than 18 years, were randomly selected from all over Spain). Socio-demographic and clinical data, survey on habits (physical activity and food consumption) and weight, height, waist, hip and blood pressure were recorder. A fasting blood draw and an oral glucose tolerance test were performed. Determinations of serum glucose were made. In the follow-up the same variables were collected and $\mathrm{HbA1c}$ was determined. A total of 2408 subjects participated in the follow-up. In total, 154 people developed diabetes (6.4\% cumulative incidence in 7.5 years of follow-up). The incidence of diabetes adjusted for the structure of age and sex of the Spanish population was 11.6 cases/1000 person-years (IC95\% $=11.1$ 12.1). The incidence of known diabetes was 3.7 cases $/ 1000$ person-years (IC95\% $=2.8-4.6$ ). The main risk factors for developing diabetes were the presence of prediabetes in cross-sectional study, age, male sex, obesity, central obesity, increase in weight, and family history of diabetes. This work provides data about population-based incidence rates of diabetes and associated risk factors in a nation-wide cohort of Spanish population.

\footnotetext{
${ }^{1}$ Spanish Biomedical Research Network in Diabetes and Associated Metabolic Disorders (CIBERDEM), Madrid, Spain. ${ }^{2}$ Biomedical Research Institute of Malaga (IBIMA), Endocrinology and Nutrition Department, Regional University Hospital of Malaga, Malaga, Spain. ${ }^{3}$ Department of Endocrinology and Nutrition, University Hospital Joan XXIII, Pere Virgili Institute (IISPV), Rovira I Virgili University, Tarragona, Spain. ${ }^{4}$ Cruces University Hospital, Biocruces Bizkaia Health Research Institute, UPV/EHU, Barakaldo, Spain. ${ }^{5}$ Spanish Biomedical Research Network in Rare Diseases (CIBERER), Madrid, Spain. ${ }^{6}$ General Laboratory. Regional University Hospital of Malaga, Malaga, Spain. ${ }^{7}$ Department of Endocrinology and Nutrition, August Pi i Sunyer Biomedical Research Institute - IDIBAPS, Hospital Clínic of Barcelona, Barcelona, Spain. ${ }^{8}$ Spanish Biomedical Research Network in physiopathology of obesity and Nutrition (CIBEROBN), Barcelona, Spain. ${ }^{9}$ Bellvitge Biomedical Research Institute (IDIBELL), University of Barcelona, Bellvitge University Hospital, Barcelona, Spain. ${ }^{10}$ Department of Endocrinology and Nutrition, Central University Hospital of Asturias/University of Oviedo, Health Research Institute of the Principality of Asturias (ISPA), Oviedo, Spain. ${ }^{11}$ Department of Endocrinology and Nutrition, Hospital del Mar, IMIM. Universitat Autònoma, Barcelona, Spain. ${ }^{12}$ Department of Applied Mathematics, Malaga University, Malaga, Spain. ${ }^{13}$ Department of Health, Public Health Agency of Catalonia, Barcelona, Spain. ${ }^{14}$ Diabetes Unit, Hospital Arnau of Vilanova, Valencia, Spain. ${ }^{15}$ Department of Endocrinology and Nutrition, Cruces University Hospital, Biocruces Bizkaia Health Research Institute, UPV/EHU, Barakaldo, Spain. ${ }^{16}$ EAP Raval Sud, Catalan Institute of Health, GEDAPS Network, Primary Care, Research support unit (IDIAP - Jordi Gol Foundation), Barcelona, Spain. ${ }^{17}$ Genomic and Genetic Diagnosis Unit, Research Foundation of Valencia University Clinical Hospital-INCLIVA, Valencia, Spain. ${ }^{18}$ Department of Endocrinology and Nutrition, University Hospital S. Carlos of Madrid, Madrid, Spain. ${ }^{19}$ These authors jointly supervised this work: J. Girbés, J. Franch-Nadal, E. Delgado, F. J. Chaves, L. Castaño and A. Calle-Pascual. *email: gemma.rojo.m@gmail.com
} 
Type 2 diabetes mellitus is one of the most serious health problems of our time. Data from numerous studies agree on the continuous growth of its incidence and prevalence rates throughout the world, with unacceptable human, social, and economic costs. Diabetes has become one of the main causes of cardiovascular disease, blindness, non-traumatic amputations of the lower limbs, kidney failure, and death throughout the world ${ }^{1}$. In addition, its association with the presence of cancer has recently been demonstrated ${ }^{2}$. Therefore, diabetes is a major challenge to public health in all countries. Understanding its epidemiology becomes supremely important for both determining the health status of the population and planning resources for their care, early diagnosis, and prevention.

The increase in the prevalence of diabetes in the world is multifactorial, and can be partly attributed to population aging, higher survival of people with diabetes due to improved medical care, and changes in lifestyle linked to increased urbanisation with sedentary behaviour and unhealthy eating profiles leading to increased obesity ${ }^{1}$. The impact of changes in lifestyle is greater in low income countries ${ }^{3}$.

A substantial proportion of people with diabetes are undiagnosed. In Europe, this group represents $37.9 \%$ of total diabetes, which, although one of the lowest in the world, means that 22 million people are at an increased risk of developing cardiovascular diseases ${ }^{1}$. In Spain, the di@bet.es study found that nearly half of the detected cases were undiagnosed diabetes ${ }^{4}$.

Most nationwide European studies on diabetes incidence are based on health service registries, and have reported incidences between 3 and 6 cases $/ 1000$ person-years ${ }^{5,6}$. However, as far as we know, there are no nation-wide population-based incidence studies on diabetes diagnosed by oral glucose tolerance test (OGTT).

Type 2 diabetes is a potentially preventable disease $\mathrm{e}^{7,8}$, and the studies on its incidence have led to examination of the variables associated with a greater risk for developing this disease. Type 2 diabetes is a polygenic disease very influenced by environmental factors and, therefore, it is necessary to perform specific population-based incidence studies, as recommended by the International Diabetes Federation (IDF) ${ }^{9}$. Of special interest are the studies at national level, which include results about the differences among natural populations and are necessary for national health systems to implement screening and prevention programs as basic tools to prevent the epidemic.

The di@bet.es study was the first national study in Spain designed with the objective of determining the prevalence and incidence of diabetes by OGTT. The results of the cross-sectional study were published in $2012^{4}$. The objective of the present study was to describe the incidence of diabetes in Spain through the re-evaluation of this cohort, as well as to examine the main risk factors related to development of diabetes.

\section{Results}

The main characteristics in the cross-sectional study of the subjects included and non-included in the incidence study are shown in Table 1. Men participated less than women and the re-evaluated subjects were one year older and had a slightly higher fasting glucose $(0.06 \mathrm{mmol} / \mathrm{L})$ than the non-participants. Participants presented more frequently a family history of diabetes, more adherence to the Mediterranean diet, and lower frequency of current smoking (more ex-smokers in this group). The rest of the variables studied were similar in both groups.

In total, 156 people developed diabetes over the 7.5 year follow-up, which yields a $6.5 \%$ cumulative incidence. The raw incidence rate in the sample was 8.5 per 1000 person-years (IC95\% $=7.3-10.1$ ) (Table 2).

The estimated incidence of diabetes adjusted for the age and sex structure of the Spanish population and the form of detection of diabetes was of 11.6 cases $/ 1000$ person-years (IC95\% $=11.1-12.1$ ). The incidence of known diabetes was 3.7 cases 1000 person-years $($ IC95\% $=2.8-4.6)$ and, therefore, the incidence of unknown diabetes was 7.9 cases $/ 1000$ person-years (IC95\% $=5.3-8.1$ ).

As expected, the incidence of diabetes increased with age and was higher among men (13.4 cases/1000 person-years IC $95 \%=12.6-14.2)$ than among women $(9.9$ cases $/ 1000$ person-years $95 \% \mathrm{CI}=9.3-10.4)$ adjusted for the form of detection of diabetes. Nevertheless, among people older than 75 years there was no difference between sexes (Fig. 1).

The OR of developing diabetes was nearly 3 -fold higher among men that among women $(\mathrm{OR}=2.7(1.6-4.5))$, adjusted for all the other variables studied (Table 2).

Both impaired fasting glucose (IFG) and impaired glucose tolerance (IGT), isolated or in combination, were risk factors associated with diabetes. There was a significant risk gradient IGT $<$ IFG $<$ IGT + IFG $(P$ for trend $<0.0001)$ in addition to a significant interaction with sex $(\mathrm{P}=0.02)$.

The presence of obesity and central obesity were related to the risk of diabetes, but overweight (BMI between 25 and $30 \mathrm{Kg} / \mathrm{m}^{2}$ ) did not reach significance; although there was a gradient in risk, as shown by the P for trend significant (Table 2). Family history of diabetes also contributed to the risk, doubling the incidence. High blood pressure, physical activity, the score of adherence to the Mediterranean diet, and dyslipidemia yielded not significant associations neither in the monovariant nor in the adjusted models (data not shown).

Since there was an interaction between the presence of dysglycemia (IFG and/or IGT) and sex in the explanation of the risk of diabetes $(\mathrm{p}<0.0001)$, we performed a stratified analysis separating each sex to reveal the interaction. The incidence of diabetes in normoglycemic men ( 7.2 cases $/ 1000$ person-years, $95 \% \mathrm{CI}=5.4-9.6)$ was significantly higher than in women $(3.1 \mathrm{cases} / 1000$ person-years, $95 \% \mathrm{CI}=2.2-4.5)$, but in presence of dysglycemia, both incidence (32.1 cases/1000 person-years, $95 \% \mathrm{CI}=21.7-45.8$ in men vs 40.4 cases/1000 person-years, $95 \% \mathrm{CI}=30.1-53.2$ in women) and adjusted OR (3.5 (1.9-6.2) in men vs $12.4(7.1-21.8)$ in women, were higher in women than in men.

\section{Discussion}

The incidence of diabetes was determined by means of a representative sample of the Spanish population and using the best available diagnostic methods (OGTT and/or HbA1c). The overall incidence adjusted for the Spanish population, and calculated taking into account that not all subjects underwent all diagnostic tests, was of 11.6 cases/ 1000 person-years. The incidence of known diabetes has only been a fraction of the total diabetes 


\begin{tabular}{|c|c|c|c|}
\hline & Non-participants & Participants & $\mathbf{p}^{\mathbf{a}}$ \\
\hline $\mathrm{n}$ & 1189 & 2408 & \\
\hline Sex (\%male) & 43.7 & 39.7 & 0.01 \\
\hline Age (years) & $46.7 \pm 16.5$ & $47.9 \pm 14.7$ & 0.03 \\
\hline BMI $\left(\mathrm{kg} / \mathrm{m}^{2}\right)$ & $27.6 \pm 5.2$ & $27.5 \pm 4.7$ & 0.7 \\
\hline Systolic blood pressure (mmHg) & $128.6 \pm 19.2$ & $128.7 \pm 18.5$ & 0.8 \\
\hline Dyastolic blood pressure $(\mathrm{mmHg})$ & $76.2 \pm 12.6$ & $76.3 \pm 10.4$ & 0.7 \\
\hline Fasting glucose $(\mathrm{mmol} / \mathrm{L})$ & $5.04 \pm 0.7$ & $5.1 \pm 0.7$ & 0.008 \\
\hline Post OGTT Glucose (mmol/L) & $5.8 \pm 1.7$ & $5.7 \pm 1.7$ & 0.4 \\
\hline Waist $(\mathrm{cm})$ & $92.4 \pm 14.2$ & $92.2 \pm 13.1$ & 0.6 \\
\hline \multicolumn{4}{|l|}{ Family history of diabetes (\%) } \\
\hline No & 54.8 & 49.8 & \multirow{3}{*}{0.009} \\
\hline Yes, one relative & 25.5 & 26.7 & \\
\hline Yes, two or more relatives & 19.7 & 23.5 & \\
\hline \multicolumn{4}{|l|}{ Physical activity (\%) } \\
\hline Low & 41.1 & 42.3 & \multirow{3}{*}{0.7} \\
\hline Moderate & 34.6 & 33.8 & \\
\hline High & 24.2 & 23.8 & \\
\hline \multicolumn{4}{|l|}{ Mediterranean diet score (14p) } \\
\hline$<8 \mathrm{p}$ & 68.4 & 64.4 & \multirow{2}{*}{0.02} \\
\hline$>=8 \mathrm{p}$ & 31.6 & 35.6 & \\
\hline \multicolumn{4}{|l|}{ Smoking (\%) } \\
\hline Never & 49.0 & 49.8 & \multirow{4}{*}{0.001} \\
\hline Former smoker & 19.1 & 24.4 & \\
\hline Current smoker less than $15 \mathrm{cig} /$ day & 15.5 & 14.5 & \\
\hline Current smoker more than $15 \mathrm{cig} /$ day & 16.4 & 11.4 & \\
\hline Dyslipidaemia (\%) & 25.7 & 26.6 & 0.5 \\
\hline Obesity (\%) & 28.1 & 26.2 & 0.1 \\
\hline Central obesity (\%) & 66.0 & 70.0 & 0.004 \\
\hline High blood pressure (\%) & 37.1 & 38.8 & 0.4 \\
\hline \multicolumn{4}{|l|}{ OGTT result (\%) } \\
\hline Normal & 86.6 & 87.8 & \multirow{4}{*}{0.3} \\
\hline IFG & 5.3 & 4.2 & \\
\hline IGT & 6.1 & 6.4 & \\
\hline IFG + IGT & 2.0 & 1.5 & \\
\hline \multicolumn{4}{|l|}{ Education level (\%) } \\
\hline None & 10.1 & 8.4 & \multirow{4}{*}{0.1} \\
\hline Basic & 49.2 & 47.4 & \\
\hline High school & 23.9 & 23.6 & \\
\hline College & 16.8 & 17.6 & \\
\hline
\end{tabular}

Table 1. Main characteristics of the population in the cross-sectional study. Comparison between participants and non-participants in the follow-up. ${ }^{\mathrm{a}} \mathrm{p}=$ signification level of $\mathrm{t}$-student, Mann-Whitney or chi2 test according to type of variable.

detected: 3.71 cases/1000 person-years, a figure that can be assimilated to the incidence of diabetes diagnosed in the national health system.

In Spain, current data about incidence of diabetes in the general population are scarce and partial. In the Lejona study, performed in the north of Spain in 1995, the incidence of diabetes was of 8.2 cases/1000 person-years 10 -year prospective study on the incidence ${ }^{10}$. In 2008 , the revaluations of two local studies were completed, one in the north (Asturias Study) ${ }^{11}$ and another one in the south (Pizarra study) $)^{12}$ of Spain. In both of them, approximately 700 subjects were followed for an average of 6-7 years. Both studies were conducted with a very similar methodology, but the incidence in the north was of 10.8 cases/1,000 person-years and in the south of 19.1 cases/1,000 person-years. One possible reason for the apparent disparity in the results of these two studies, practically contemporaneous, could be the higher prevalence and incidence of obesity in the population of Pizarra, where the mean weight gain during the follow-up doubled the one of the Asturias study ${ }^{11,12}$. The results that we present from the di@bet.es cohort are concordant with the studies carried out in the north, but lower than those carried out in the south of Spain. In our cohort, the diabetes prevalence has been previously shown to be higher in the south of Spain compared to the other parts of the country ${ }^{11}$. 


\begin{tabular}{|c|c|c|c|c|c|c|}
\hline & $\begin{array}{l}\mathrm{N}^{\circ} \text { at } \\
\text { risk }\end{array}$ & $\begin{array}{l}\mathrm{n}^{\circ} \text { developing } \\
\text { diabetes }\end{array}$ & person/years & $\begin{array}{l}\text { Incidence rate per } 1000 \\
\text { person-years }(95 \% \mathrm{CI})\end{array}$ & $\mathrm{OR}^{\mathrm{a}}(95 \% \mathrm{CI})$ & $\mathrm{OR}^{\mathrm{b}}(95 \% \mathrm{CI})$ \\
\hline All sample & 2408 & 156 & 18088 & $8.6(7.3-10.1)$ & - & - \\
\hline \multicolumn{7}{|l|}{ Sex } \\
\hline Women & 1451 & 81 & 10883 & $7.4(5.9-9.3)$ & Ref. cat. & Ref. cat. \\
\hline Men & 957 & 75 & 7205 & $10.4(8.2-13)$ & $1.5(1.1-2.1)$ & $2.7(1.6-4.5)$ \\
\hline \multicolumn{7}{|l|}{ OGTT result } \\
\hline Normoglycemia & 2115 & 75 & 15892 & $4.7(3.7-5.9)$ & Ref. cat. & Ref. cat. \\
\hline Isolated IGT & 154 & 35 & 1156 & $30.3(21.1-42.1)$ & $10.8(5.7-20.2)$ & $7.9(4-15.5)$ \\
\hline Isolated IFG & 102 & 27 & 761 & $35.5(23.4-51.6)$ & $14.4(7.5-27.6)$ & $11.7(5.9-23.3)$ \\
\hline Combined IFG-IGT & 37 & 19 & 278 & $68.3(41.1-106.6)$ & $42.3(16.3-109.5)$ & $48.8(17.1-139.8)$ \\
\hline $\mathrm{P}$ for trend & & & & & $<0.0001$ & $<0.0001$ \\
\hline \multicolumn{7}{|l|}{ Obesity } \\
\hline $\mathrm{BMI}<25 \mathrm{~kg} / \mathrm{m}^{2}$ & 749 & 15 & 5628 & $2.7(1.5-4.4)$ & \begin{tabular}{|l|} 
Ref. cat. \\
\end{tabular} & Ref. cat. \\
\hline BMI $25-30 \mathrm{~kg} / \mathrm{m}^{2}$ & 1018 & 57 & 7662 & $7.4(5.6-9.6)$ & $1.9(0.9-3.9)$ & $1.2(0.6-2.3)$ \\
\hline $\mathrm{BMI} \geq 30 \mathrm{~kg} / \mathrm{m}^{2}$ & 626 & 82 & 4691 & $17.5(13.9-21.7)$ & $4.6(2.3-9.2)$ & $2.3(1.1-4.6)$ \\
\hline $\mathrm{P}$ for trend & & & & & $<0.0001$ & $<0.0001$ \\
\hline \multicolumn{7}{|c|}{ Central obesity (Waist $\geq 94 \mathrm{~cm}$ in men and $\geq 80 \mathrm{~cm}$ in women) } \\
\hline No & 718 & 8 & 5400 & $1.5(0.6-2.9)$ & Ref. cat. & Ref. cat. \\
\hline Yes & 1677 & 146 & 12596 & $11.6(9.8-13.6)$ & $10.6(2.6-43.5)$ & $3.4(1.5-7.8)$ \\
\hline \multicolumn{7}{|c|}{ Family History of diabetes (first-degree relatives) } \\
\hline No & 1569 & 73 & 11794 & $6.2(4.9-7.8)$ & Ref. cat. & Ref. cat. \\
\hline Yes & 839 & 83 & 6294 & $13.2(10.5-16.3)$ & $2.4(1.5-3.9)$ & $2.3(1.6-3.3)$ \\
\hline
\end{tabular}

Table 2. Incidence of diabetes according to the main exposure factors present in the cross-sectional study. ${ }^{\mathrm{a}} \mathrm{ORs}$ were calculated for each variable by logistic regression adjusted for age and sex (sex was adjusted for age). ${ }^{b}$ ORs were calculated using a single logistic regression model (all variables listed are introduced in the analysis at once) and additionally adjusted for presence of high blood pressure, level of physical activity (IPAQ), education level, and Mediterranean diet score. Ref. cat. = Reference category.

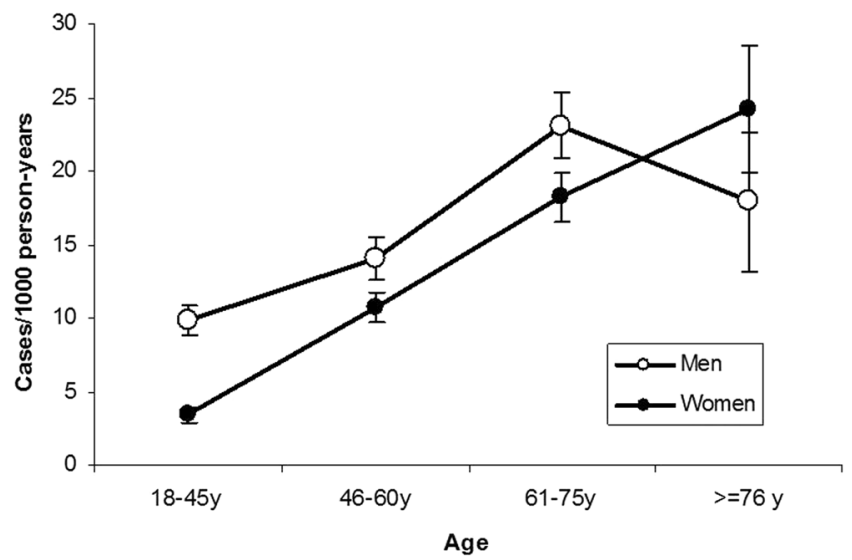

Figure 1. Incidence of diabetes according to sex and age, adjusted for diagnostic method.

In 2013, data on the incidence of diabetes from the Spanish participants in the EPIC cohort, made up of voluntary donors from several Spanish localities followed for 12 years, were published ${ }^{13}$. Adjusted rates varied between 4.2 and 7.2 cases/1000persons-year in men and 3.5 and 4.3 cases/1,000 person-years in women, with abdominal obesity being one of the main risk factors. These lower incidence rates with respect to population-based studies may be due to the sample selection, since the EPIC comprised healthy volunteers (blood donors and workers), while in the other Spanish studies, including the present results, sampling was composed of general population, not necessarily healthy. The diagnosis of diabetes by OGTT also increases the number of incident cases. The wide population studies that use this diagnostic tool are very scarce. Something similar happens with the study based on the working population recently published in Spain "Incidence of Diabetes in the Working Population in Spain"14: the incidence (5.0 cases/1000 person-years) was very low and similar to the one found in EPIC and other studies in which the working population was mainly involved.

There are no studies on the incidence of diabetes in Europe as a whole, and only few countries have data at a national level, usually based on health records. The study by Norhammar et al. ${ }^{5}$ in Sweden, with an overall 
incidence of 4.2 per 1000 person-years, or the study by Holst ${ }^{6}$ in Denmark, with incidences of 6.2 in men and 4.4 in women, are examples of this, but their findings are clearly lower than those of our study. The IDF estimates that the prevalence of diabetes in Europe will increase by $16 \%$ between 2017 and $2045^{\circ}$. This estimate is equivalent to an incidence rate of 4.2 cases/1000 person-years, similar to the one calculated for diagnosed diabetes by health systems that do not usually use OGTT as a diagnostic method. The incidence of diabetes in these works is similar to the incidence of previously known diabetes in our study (3.7 cases/1000 person-years).

The studies conducted in Europe (mostly local) in the last years, based on glucose determinations and rarely using OGTT, reveal the heterogeneity of diabetes incidence among the different studies ${ }^{14-22}$ ranging from 5 per 1000 cases of the ICARIA study ${ }^{14}$ in working population, to more than 17 per 1000 of the Hoorn study ${ }^{18}$ with OGTT in a population with mean age around 60 years old. These differences may be due to (besides the methodology) the important differences between countries in the prevalence of obesity, physical activity, or eating patterns, which might partially explain the variation in diabetes prevalence ${ }^{23}$. On the other hand, our incidence rates are clearly lower than those reported for high risk populations, like the North-american ${ }^{19,24}$.

In the di@bet.es study, the variables associated with the presence of diabetes in the cross-sectional study were age, sex, educational level, obesity, abdominal obesity, hypertension, low levels of HDL cholesterol, and high levels of triglycerides as well as the family history of diabetes ${ }^{4}$. In the current work, most of these variables are also associated with incident diabetes, except for hypertension and dyslipidemia. This may be due to the fact that these variables are not causative of diabetes, but they rather share a common pathophysiology, probably linked to the loss of insulin sensitivity ${ }^{25}$. The main predictor variable has been the presence of dysglicemia in the baseline study, as it happened in other studies ${ }^{14,17,18,26}$. The presence of IGT conferred a lower risk than IFG, while the combination of both multiplied the risk of developing diabetes, especially in women. A similar effect has been found in the ADDITION-Denmark study ${ }^{26}$. The importance of detecting an early dysglicemia lies not only in the increased risk of developing diabetes over time, but also in the higher risk of developing cardiovascular and renal disease, and the higher mortality than normoglycemic subjects ${ }^{27}$. In our work, the risk associated with the presence of IGT or IFG is somewhat higher than the one described in the meta-analysis by Gerstein ${ }^{28}$.

Important differences have been found in the prevalence and incidence of diabetes according to $\operatorname{sex}^{3}$. In women, the incidence rates were lower than in men, but only in normoglycemic women. However, the presence of dysglycemia increased much more the risk in women that became statistically equal to men, and resulted in a significantly higher OR (significant interaction disglycemia $\mathrm{x} \mathrm{sex}$ ), which, as far as we know, has not been described in other studies.

The ability of glucose post-OGTT to predict diabetes, together with its relationship with mortality and cardiovascular risk ${ }^{29}$, makes it one of the main risk factors to be taken into account, although the complexity of its measurement makes it an invalid test for screening. In our study, glucose post OGTT predicted the risk of diabetes incidence, and, as already mentioned, its simultaneous alteration with basal glycemia multiplied the risk.

Overall and central obesity were independently associated with diabetes. It has been shown ${ }^{30}$ that, from a certain age, obesity is associated with a reduction in the years of life free of diabetes and an increase in the years lived with diabetes.

The adjustment of the models with the family history of diabetes, the presence of high blood pressure, the adherence to the Mediterranean diet, or the intensity of physical exercise hardly modify the magnitude of the OR of the models adjusted only for age and sex. In our study, we did not find a direct effect of adherence to the Mediterranean diet and the level of physical activity on the incidence of diabetes. This may possibly be due to the limited sample size or the lack of precision of some variables as synthetic as the ones used.

The strengths of this study are that the sample has been chosen randomly from all over Spain, with people aged 18 and over, most of whom underwent an OGTT to diagnose diabetes. In the follow-up, HbA1c was also used, which guarantees the capture of most of the incident diabetes. Most published studies on diabetes incidence perform incidence estimates based on health records or self-reported diabetes and therefore may underestimate the real incidence of diabetes ${ }^{5,6,26,31,32}$.

Some limitations deserve mention. Our sample is composed of white people and, therefore, it cannot be generalised to other ethnic groups. The participation in the follow-up was of $66 \%$, however, we have found few differences between people who participated in the follow-up and those who did not, and as a result, the possible participation bias has been minimal. Moreover, diabetes incidence in Spain may not be representative of other countries due to different dietary habits, physical exercise, or genetic background, although these variables have much less influence on the risk of diabetes than the presence of obesity or previous dysglycemia.

Spain has one of the highest life expectancies in the world (only less than Japan and Switzerland) and one of the lowest cardiovascular disease mortality rates in Europe, despite the high rates of metabolic diseases (obesity, diabetes, or hypertension) found in this and other studies ${ }^{33}$. This apparent paradox can be explained by the interaction between the genetic variants selected over centuries in the Mediterranean area with changes in current lifestyles (abandonment of the Mediterranean diet and sedentary lifestyle) ${ }^{34}$, issues that need additional research to be answered.

In conclusion, this work provides data about population-based rates of diabetes incidence and associated risk factors in a nation-wide cohort from Spanish population.

\section{Methods}

Study design, setting and population. The di@bet.es epidemiological trial is a population based cohort study. The initial cross-sectional study was undertaken between 2008 and 2010 using a random cluster sampling of Spanish population ${ }^{4}$. The sample size was calculated assuming a diabetes prevalence of $15 \%$ of the population, with an error lower than 1\%. The di@bet.es study sample consisted of 5072 subjects older than 18 years, randomly selected from the National Health System registries distributed into 100 clusters (primary health care centres). 


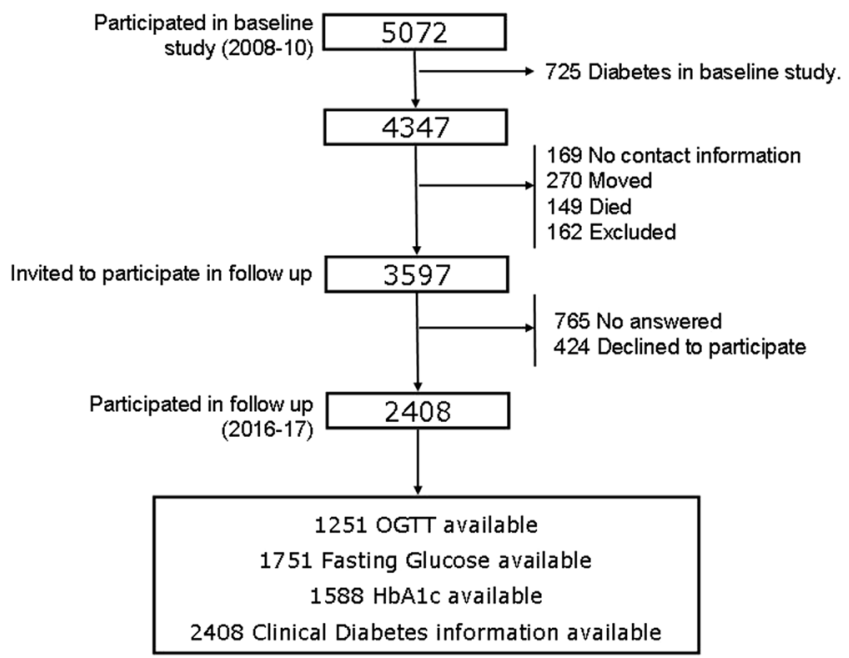

Figure 2. Participation flow chart.

Exclusion criteria in the cross-sectional study were: serious illness, pregnancy, recent delivery or lactation, surgery within the previous month, or any other disabling situation that prevented participation.

The cohort was re-evaluated in 2016-17 (follow-up time was $7.5 \pm 0.6$ years). All subjects who had completed the baseline study $(\mathrm{n}=5072)$ were invited by letter and by phone to attend another clinical examination. The 725 subjects who had diabetes at baseline were excluded from all the incidence calculations. Thus, the at-risk sample included 4347 people. As with the cross-sectional study, people with serious illness, pregnancy, recent delivery or lactation, or surgery within the previous month were excluded. Finally, 2408 subjects completed the follow-up (Fig. 2).

The research was carried out in accordance with the Declaration of Helsinki (2008) of the Word Medical Association. Both the cross-sectional study and the follow-up study were approved by the Ethics and Clinical Research Committee of the Hospital Regional Universitario de Malaga (Malaga, Spain). All the participants were informed about the nature of the study and provided written informed consent in the two phases of the study, document approved by the committee mentioned above.

Procedures. The participants were invited to attend a single examination visit at their health centre with a nurse specially trained for this project. Information was collected using an interviewer-administered structured questionnaire, followed by a physical examination, blood sampling, and an oral glucose tolerance test (OGTT).

A structured questionnaire included closed questions was used to collect the following data: sex, age, instruction level (none, basic, high school or college), personal history of diabetes (yes/no), high blood pressure (yes/no) and dyslipidemia (yes/no), family history of diabetes (yes/no), medications, specifically asking about diabetes, high blood pressure or dyslipidemia medication; frequency of food consumption, and physical activity.

The physical examination included measurement of body weight, height, and waist and hip circumferences that were performed using standardised methods ${ }^{35}$. Besides, body mass index $\left(\mathrm{BMI}=\right.$ weight $/$ height $\left.^{2}\right)$, and waist to hip ratio (WHR) were calculated. Blood pressure was measured with the subject seated after 5 minutes of rest and 2 minutes after the first measurement. A third measure was performed if there was a difference greater than $10 \%$ between the first two measurements.

Participants with baseline capillary blood glucose levels lower than $7.8 \mathrm{mmol} / \mathrm{L}$ (measured by OneTouch ${ }^{\circledR}$ sys- $^{-}$ tem, Lifescan, Johnson \& Johnson, S.A., Madrid), and not receiving treatment for diabetes, underwent a standard oral glucose tolerance test (OGTT) with $75 \mathrm{~g}$ of glucose dissolved in $200 \mathrm{ml}$ of water. In this way, fasting and $2 \mathrm{~h}$ venous samples were obtained ( 8 to 10 hours fasting samples were obtained between 8:30am and 10:00 am in gel tubes suitable with a vacuum blood extraction system), the samples were allowed to stand for $30^{\prime}$. After centrifugation, the serum was separated from the clot and frozen (in cross-sectional study) or refrigerated (in follow up). All samples were analyzed in the same central laboratory after shipment through a specialized courier (Cerba International Laboratory in Barcelona) in the cross-sectional study, and the General Laboratory of the Hospital Regional Universitario of Malaga in the follow-up). In both stages, glucose was determined by the hexokinase enzymatic method, total cholesterol by cholesterol oxidase enzymatic method, HDL cholesterol by direct method, triglycerides by glycerol phosphate oxidase enzymatic method, LDL cholesterol was calculated by Friedewald formula. HbA1C by high-performance liquid chromatography (analyzer ADAMS A1C HA-8180V, ARKRAY ${ }^{\mathrm{R}}$ ) were measured only in follow up study.

The samples were deposited in the Biobank of the Hospital Regional Universitario de Malaga-IBIMA, which belongs to the Andalusian Public Health System Biobank, and the biorepository CIBERDEM managed by IDIBAPS Biobank (Barcelona, Spain).

In follow up, people who did not want to fully participate in the complete study were asked to take a short survey in order to collect information about the drugs they were taking (to determine the existence of clinical diabetes, hypertension or dyslipidemia in treatment), if they were on some type of diet, and self-reported weight. 
Assessment of outcomes in follow up. Incident diabetes was defined as fasting serum glucose equal or higher than $7 \mathrm{mmol} / \mathrm{L}$ or 2 hour post load serum glucose equal or higher than $11 \mathrm{mmol} / \mathrm{L}$ or $\mathrm{HbA} 1 \mathrm{c}$ equal or higher than $6.5 \%(47.54 \mathrm{mmol} / \mathrm{molHb})$ or use of glucose-lowering medication at the follow-up examination ${ }^{36}$. "Known diabetes" was established when the subject reported having diabetes and/or being treated with diabetes drugs.

Main risk/exposure factors. The following variables from cross-sectional study were considered: first, glucose impairment category in the cross-sectional study: subjects were classified according to their blood glucose as having a normal OGTT or impaired fasting glucose (IFG) or impaired glucose tolerance (IGT), or both following Alberti and Zimmet ${ }^{37}$. Second, obesity (BMI equal or higher than $30 \mathrm{~kg} / \mathrm{m}^{2}$ ) or overweight (BMI between 25 and $\left.30 \mathrm{~kg} / \mathrm{m}^{2}\right)$. Third, central obesity presence defined as waist circumference $>94 \mathrm{~cm}$ in men or $>80 \mathrm{~cm}$ in women ${ }^{38}$.

Secondary exposure factors and potential confounders. The following variables from cross-sectional study were recorded: age, educational level (none, basic, high school or college), physical activity by the International physical activity questionnaire (IPAQ) ${ }^{39}$, smoking (current, ex- or never smoker), high blood pressure (blood pressure equal or higher $140 / 90 \mathrm{mmHg}$ or receiving antihypertensive treatment), dyslipidemia (triglycerides were equal or higher $1.7 \mathrm{mmol} / \mathrm{L}$ or HDL cholesterol less than $1.03 \mathrm{mmol} / \mathrm{L}$ in men or less than $1.29 \mathrm{mmol} / \mathrm{L}$ in women or medication), and family history of diabetes (at least one first degree relative with diabetes). A qualitative food frequency questionnaire was administered face-to-face by a trained dietitian ${ }^{40}$. Annual frequency consumption of 50 food items was specified in 11 different categories as follows: never/seldom, 1 and 2-3 times/month, 1, 2-3 and 4-6 times/week and 1, 2, 3, 4 and $>4$ times/day, and a 14-point Mediterranean diet score was calculated.

Statistical analysis. Data are presented as means \pm SD, or proportions. Differences in baseline variables according to participation in follow-up were determined by the $t$-test for independent samples, the MannWhitney test, or $\mathrm{chi}^{2}$ test when appropriate. The sample incidence rates (IRs) were calculated as number of events/ person-time at risk for diabetes, assuming a constant incidence over time. The estimation of the population incidence rate was calculated taking into account that not all the participants were diagnosed with the four possible criteria (previous diabetes diagnosed after the cross-sectional study, fasting glucose, postload glucose or HbAlc) and adjusted for sex and age by direct method using as reference the Spanish population (https://www.ine.es/, accessed June 2009).

Multivariate analysis was performed using logistical regression for odd ratios (ORs) calculation adjusted for potential confounders. The test of Hosmer and Lemeshow was used to check the goodness of fit. For IRs and ORs, 95\% confidence intervals were computed. Analyses were made using SPSS v20 (IBM., Chicago, IL, USA).

\section{Data availability}

The datasets generated during and/or analyzed during the current study are available from the corresponding author on reasonable request.

Received: 15 September 2019; Accepted: 28 January 2020;

Published online: 17 February 2020

\section{References}

1. Cho, N. H. et al. IDF Diabetes Atlas: Global estimates of diabetes prevalence for 2017 and projections for 2045. Diabetes Res. Clin. Pract. 138, 271-281 (2018).

2. Ohkuma, T., Peters, S. A. E. \& Woodward, M. Sex differences in the association between diabetes and cancer: a systematic review and meta-analysis of 121 cohorts including 20 million individuals and one million events. Diabetologia 61, 2140-2154 (2018).

3. NCD Risk Factor Collaboration (NCD-RisC). Worldwide trends in diabetes since 1980: a pooled analysis of 751 population-based studies with 4.4 million participants. Lancet 387, 1513-1530 (2016).

4. Soriguer, F. et al. Prevalence of diabetes mellitus and impaired glucose regulation in Spain: the Di@bet.es Study. Diabetologia 55, $88-93$ (2012).

5. Norhammar, A. et al. Incidence, prevalence and mortality of type 2 diabetes requiring glucose-lowering treatment, and associated risks of cardiovascular complications: a nationwide study in Sweden, 2006-2013. Diabetologia 59, 1692-1701 (2016).

6. Holst, C., Becker, U., Jørgensen, M. E., Grønbaek, M. \& Tolstrup, J. S. Alcohol drinking patterns and risk of diabetes: a cohort study of 70,551 men and women from the general Danish population. Diabetologia 60, 1941-1950 (2017).

7. Costa, B. et al. Delaying progression to type 2 diabetes among high-risk Spanish individuals is feasible in real-life primary healthcare settings using intensive lifestyle intervention. Diabetologia 55, 1319-1328 (2012).

8. Soriguer, F., Rubio-Martín, E. \& Rojo-Martínez, G. Prevención de la diabetes mellitus tipo 2. Med. Clin. (Barc). 139, 640-646 (2012).

9. International Diabetes Federation. IDF DIABETES ATLAS. 8th edition 2017. (2018)

10. Vázquez, J. A., Gaztambide, S. \& Soto-Pedre, E. 10-year prospective study on the incidence and risk factors for type 2 diabetes mellitus. Med. Clin. (Barc). 115, 534-9 (2000).

11. Valdés, S., Botas, P., Delgado, E., Álvarez, F. \& Cadórniga, F. D. Population-based incidence of type 2 diabetes in northern Spain: The Asturias study. Diabetes Care 30, 2258-2263 (2007).

12. Soriguer, F. et al. Incidence of type 2 diabetes in southern Spain (Pizarra Study). Eur. J. Clin. Invest. 38, 126-133 (2008).

13. Huerta, J. M. et al. Risk of type 2 diabetes according to traditional and emerging anthropometric indices in Spain, a Mediterranean country with high prevalence of obesity: results from a large-scale prospective cohort study. BMC Endocr. Disord. 13, 7 (2013).

14. Vazquez, L. A. et al. Incidence of Diabetes in the Working Population in Spain: Results from the ICARIA Cohort. Diabetes Ther. 10, 57-6 (2019).

15. Sans, S., Padró, T., Tuomilehto, J. \& Badimon, L. Incidence of diabetes and serum adipokines in Catalonian men: the ADIPOCAT study. Ann. Med. 45, 97-102 (2013).

16. Bombelli, M. et al. Uric acid and risk of new-onset metabolic syndrome, impaired fasting glucose and diabetes mellitus in a general Italian population: Data from the Pressioni Arteriose Monitorate e Loro Associazioni study. J. Hypertens. 36, 1492-1498 (2018).

17. Koloverou, E. et al. Dietary patterns and 10-year (2002-2012) incidence of type 2 diabetes: Results from the ATTICA cohort study. Rev. Diabet. Stud. 13, 246-256 (2016). 
18. Ruijgrok, C. et al. Size and shape of the associations of glucose, HbA1c, insulin and HOMA-IR with incident type 2 diabetes: the Hoorn Study. Diabetologia 61, 93-100 (2018).

19. Selvin, E., Wang, D., Lee, A. K., Coresh, J. \& Bergenstal, R. M. Identifying Trends in Undiagnosed Diabetes in USAdults. Ann. Intern. Med. 168, 900 (2018).

20. Ikram, M. A. et al. The Rotterdam Study: 2018 update on objectives, design and main results. Eur. J. Epidemiol. 32, 807-50 (2017).

21. Abraham, T. M., Pencina, K. M., Pencina, M. J. \& Fox, C. S. Trends in diabetes incidence: The framingham heart study. Diabetes Care. 38, 482-7 (2015).

22. Forouhi, N. G., Luan, J., Hennings, S. \& Wareham, N. J. Incidence of Type 2 diabetes in England and its association with baseline impaired fasting glucose: The Ely study 1990-2000. Diabet. Med. 24, 200-207 (2007).

23. Varo, J. J. et al. Distribution and determinants of sedentary lifestyles in the European Union. Int. J. Epidemiol. 32, 138-146 (2003).

24. González-Villalpando, C., Dávila-Cervantes, C. A., Zamora-Macorra, M., Trejo-Valdivia, B. \& González-Villalpando, M. E. Incidence of type 2 diabetes in Mexico. Results of The Mexico City Diabetes Study after 18 years of follow up. Salud Pública Méx 56, 11-17 (2014).

25. Yaribeygi, H., Farrokhi, F. R., Butler, A. E. \& Sahebkar, A. Insulin resistance: Review of the underlying molecular mechanisms. J. Cell Physiol. 234, 8152-8161 (2019).

26. Rasmussen, S. S. et al. Incidence of register-based diabetes 10 years after a stepwise diabetes screening programme: the ADDITIONDenmark study. Diabetologia 59, 989-997 (2016).

27. Warren, B. et al. Comparative prognostic performance of definitions of prediabetes: a prospective cohort analysis of the Atherosclerosis Risk in Communities (ARIC) study. Lancet Diabetes Endocrinol. 5, 34-42 (2017).

28. Gerstein, H. C. et al. Annual incidence and relative risk of diabetes in people with various categories of dysglycemia: A systematic overview and meta-analysis of prospective studies. Diabetes Res. Clin. Pract. 78, 305-312 (2007).

29. DECODE Study Group. Glucose Tolerance and Cardiovascular Mortality. Arch. Intern. Med. 161, 397-405 (2001).

30. Dhana, K. et al. Obesity and Life Expectancy with and without Diabetes in Adults Aged 55 Years and Older in the Netherlands: A Prospective Cohort Study. Plos Med. 13, e1002086 (2016).

31. Muhammad, I. F. et al. Arterial stiffness and incidence of diabetes: A population-based cohort study. Diabetes Care 40, 1739-1745 (2017).

32. Gil-Montalbán, E. et al. Incidencia de diabetes tipo 2 y factores asociados en la población adulta de la Comunidad de Madrid. Cohorte PREDIMERC. Rev. Clin. Española 215, 495-502 (2015).

33. Grau, M. et al. Factores de riesgo cardiovascular en España en la primera década del siglo XXI: análisis agrupado con datos individuales de 11 estudios de base poblacional, estudio DARIOS. Rev. Esp. Cardiol. 64, 295-304 (2011).

34. Soriguer, F. et al. Mediterranean diet and the Spanish paradox. A hypothesis. Med. Hypotheses 80, 150-155 (2013).

35. WHO Expert Commettee on Physical Status. Physical Status: The Use and Interpretation of Anthropometry: report of a WHO expert committee. In WHO Technical Report Series: 854, 452 (1995).

36. American-Diabetes-Association. Classification and Diagnosis of Diabetes: Standards of Medical Care in Diabetes-2019. Diabetes Care 42, S13-S28 (2019).

37. Alberti, K. G. M. M. \& Zimmet, P. Z. Definition, diagnosis and classification of diabetes mellitus and its complications. Part 1: diagnosis and classification of diabetes mellitus. Provisional report of a WHO Consultation. Diabet. Med. 15, 539-553 (1998).

38. Eckel, R. H., Grundy, S. \& Zimmet, P. Z. The metabolic syndrome. Lancet 365, 1415-28 (2005).

39. Craig, C. L. et al. International physical activity questionnaire: 12-Country reliability and validity. Med. Sci. Sports Exerc. 35, 1381-1395 (2003)

40. Rojo-Martínez, G. et al. Serum sCD163 levels are associated with type 2 diabetes mellitus and are influenced by coffee and wine consumption: Results of the di@bet.es study.Plos One 9, e101250 (2014).

\section{Acknowledgements}

Our most sincere thanks to Isabel Ramis (Spanish Biomedical Research Network in Diabetes and Associated Metabolic Disorders (CIBERDEM). Barcelona. Spain) for her help at all times in the organisation of the study. Our profound appreciation goes to the primary care managers and personnel of the participating health centres, and very especially to L Forga (Complejo Hospitalario de Navarra, Pamplona Spain), F Casanueva (Complejo Hospitalario Universitario de Santiago, Santiago de Compostela, Spain), JJ Alemán (Dirección General de Salud Pública del Servicio Canario de la Salud, Palmas de Gran Canaria, Spain), J Marzo (Dirección General de Asistencia Sanitaria, Zaragoza, Spain), JM Millaruelo (Centro de Salud Torrero-La Paz, Zaragoza, Spain), J García-Rotllán (Dirección General de Asistencia Sanitaria y Resultados en Salud, Sevilla, Spain), MA Ayuso (Ayuntamiento de Villamanrrique de Tajo, Spain), MB Ballesteros (Hospital General Universitario de León, Spain), L Jolín (Dirección de Atención Primaria, Palencia), M Moreiras (Hospital Universitario de Palencia, Spain), J Parra (Hospital de Mérida, Spain), C Jiménez (Dirección de Atención Primaria, Cáceres, Spain), and MJ Gamero (Dirección de Atención Primaria, Badajoz, Spain). To all the fieldworkers, nurses, and technicians, without whose work the study would not have been possible. We are indebted to the technical staff of the UGC of Laboratories of the Hospital Regional Universitario of Málaga, for their invaluable technical assistance. We are grateful to Claudia Corazza (Biomedical Research Institute of Malaga, Spain), for help with the English language version of the manuscript. We are very grateful to Patricia González (Biomedical Research Institute of Malaga, Spain), for help with the databases, and to all the people who voluntarily participated in the study. We are indebted to the Biobank of the Hospital Regional Universitario of Malaga-IBIMA and CIBERDEM Biorepository (IDIBAPS Biobank), integrated in the Spanish National Biobank Network, for the samples management. Supported by CIBERDEM (Ministerio de Economía, Industria y Competitividad-ISCIII), Ministerio de Sanidad, Servicios Sociales e Igualdad-ISCIII, Instituto de Salud Carlos III (PI14/00710, PI14/01104, PI14/00970, PI14/00874, PIE14/00031, PI17/02136), European Regional Development Fund (ERDF) "A way to build Europe", PERIS Grant No. SLT002/16. LifeScan España (Madrid, Spain) kindly donated the glucometers and test strips for capillary glucose measurements. There is no potential conflict of interest related to project funding.

\section{Author contributions}

Conception and design: G. Rojo-Martínez, S. Valdés, F. Soriguer, J. Girbés, S. Gaztambide, J. Franch-Nadal, E. Delgado, F.J. Chaves, L. Castaño and A. Calle. Acquisition of data: J. Vendrell, I. Urrutia, V. Pérez, E. Ortega, P. Ocón, E. Montanya, E. Menéndez, A. Lago-Sampedro, T. González- Frutos, R. Gomis, A. Goday, S. GarcíaSerrano, E. García-Escobar, J.L. Galán-García, C. Castell, R. Badía and G. Aguilera-Venegas. Analysis and interpretation of data: G. Rojo-Martínez, S. Valdés and F. Soriguer. Drafting the article: G. Rojo-Martínez, S. 
Valdés and F. Soriguer. Review for important intellectual content: J. Vendrell, I. Urrutia, V. Pérez, E. Ortega, P. Ocón, E. Montanya, E. Menéndez, A. Lago-Sampedro, T. González- Frutos, R. Gomis, A. Goday, S. GarcíaSerrano, E. García-Escobar, J.L. Galán-García, C. Castell, R. Badía, G. Aguilera-Venegas, J. Girbés, S. Gaztambide, J. Franch-Nadal, E. Delgado, F.J. Chaves, L. Castaño and A. Calle. All authors have reviewed and approved the final version of the manuscript. Gemma Rojo-Martínez is the guarantor of this work.

\section{Competing interests}

E.M. has been on advisory boards, has received consulting fees, speaker honoraria or research support from Astra Zeneca, Menarini Laboratories, Merck Sharp \& Dohme, Novartis, NovoNordisk and Sanofi. None of the other authors declare having financial or not financial competing interests, related to this work.

\section{Additional information}

Correspondence and requests for materials should be addressed to G.R.-M.

Reprints and permissions information is available at www.nature.com/reprints.

Publisher's note Springer Nature remains neutral with regard to jurisdictional claims in published maps and institutional affiliations.

(c) Open Access This article is licensed under a Creative Commons Attribution 4.0 International License, which permits use, sharing, adaptation, distribution and reproduction in any medium or format, as long as you give appropriate credit to the original author(s) and the source, provide a link to the Creative Commons license, and indicate if changes were made. The images or other third party material in this article are included in the article's Creative Commons license, unless indicated otherwise in a credit line to the material. If material is not included in the article's Creative Commons license and your intended use is not permitted by statutory regulation or exceeds the permitted use, you will need to obtain permission directly from the copyright holder. To view a copy of this license, visit http://creativecommons.org/licenses/by/4.0/.

(c) The Author(s) 2020 